Sircar, S. M., and P. M. Samantaray. 1942. Effect of photoperiodic induction on growth and carbohydrate metabolism of rice. Unpublished. Cited by Sircar in Vernalization and photoperiodism. 1948. Chronica Botanica Co. Waltham, Mass.

Thimann, K. V., and F. Skoog. 1934. The inhibition of bud development and other functions of growth substances in Vicia Faba. Proc. Roy. Soc. London B 114: 317-339.

Watson, S. 1891. Contributions to American botany. III. Upon a wild species of $Z e a$ from Mexico. Proc. Amer. Acad Arts and Sci. 26: 124-163.

\title{
STOMATA ON THE OVULES OF ZAMIA FLORIDANA ${ }^{1}$
}

\section{Seymour Shapiro}

IN THE OVULES of certain fossil pteridosperms the nucellus appears as a prominent tissue often projecting through a wide micropyle up to, and even beyond, the outer limits of the integument. Oliver and Scott (1903) report that in Lagenostoma Lomaxi the nucellus reaches to the exterior, ". . . plugging the micropylar aperture like a cork." In modern cycads, however, the nucellus is a much less conspicuous tissue, evolutionarily modified to the extent that it is now considered completely internal. The thick integument and very narrow micropyle make the physiologic environment of the nucellus essentially that of an internal tissue. In view of the present nature and much reduced state of the nucellus, the observation that stomata are present on the epidermis of this tissue, in the ovule of Zamia floridana, was deemed significant and worthy of report. A previous account (Shapiro, 1949) revealed the presence of stomata on the nucellus and also on the integument of the ovule of Zamia. This paper deals with the character of these stomata and with certain phylogenetic implications of their presence.

Materials AND Methods.-The strobili of Zamia floridana upon which this study. is based were collected in Gainesville, Florida by Prof. G. Weber of the University of Florida. Collections made in 1946, 1947, 1949, and 1950 were utilized and material in different stages of development was available. The earlier collections (1946, 1947, and 1949) were primarily of relatively late stages in development. The 1950 material supplemented these with prepollination and pollination stage ovules.

Many of the observations were made directly from the fresh material either by peeling off the epidermis, or, more commonly, by inverting the nucellus and scraping away completely the soft underlying parenchyma. The epidermis remains intact because of the protection afforded by the

1 Received for publication April 18, 1950.

Paper from the Department of Botany, University of Michigan, No. 912.

The author wishes to thank Prof. C. D. La Rue for his aid and criticism and also for supplying much of the material used in this study.

The author is indebted to the Heredity Clinic of the Laboratory of Vertebrate Biology of the University of Michigan for making available their photographic equipment and supplies. heavy cuticle. A number of ovules and excised nucelli were fixed in formalin-aceto-alcohol and Randolph's Modified Navashin fixatives. Serial sections were cut at $12 \mu$ following tertiary butyl alcohol dehydration and paraffin embedding. All prepared slides were stained with safranine and fast green. Some of the ovules and dissected-out nucelli were cleared in lactic acid and used to supplement the surface view observations made from fresh material.

Nature of the stomata. - The integument of the ovule of Zamia floridana is large and very thick, often exceeding $1 \mathrm{~cm}$. in thickness at the micropylar end. In median longitudinal view of an unfertilized but fully grown ovule (fig. 1), the micropyle (fig. la) is seen as an extremely thin canal running through the integument and terminating inside the ovule at the pollen chamber (fig. lc). The nucellus (fig. ld), free from the integument at its apical end, is a small mass of tissue forming the floor of the pollen chamber and cap. ping the large female gametophyte (fig. If). The apical region of the nucellus is about fifty cells in thickness. The nucellus becomes much thinner in its downward extent over the sides of the female gametophyte, and is only a few cells thick where it joins the integument (fig. 2). The free portion of the nucellus can easily be removed from the ovule (fig. 3 ). When the nucellar epidermis is examined in surface view, it discloses the presence of numerous stomata. The stomata show no pattern of distribution but appear to be more numerous in a central band which extends from a little way below the nucellar beak to a short distance above the junction of the nucellus with the integument. The epidermal cells of the nucellar beak and of the region immediately below the beak are similar in shape but smaller in size than are the cells comprising the major portion of the nucellar epidermis. The smaller cells apparently never form stomata and may indicate an area that attains maturity prior to the stage of stomatal development. Young ovules (in late stages of free nuclear division of the gametophyte) show the smaller apical cells as possessing thick walls, a thin cytoplasm, and small nuclei. The areas nearer the base of the nucellus have more meristematic cells with thinner walls, dense cytoplasm, and large nuclei. In mature 

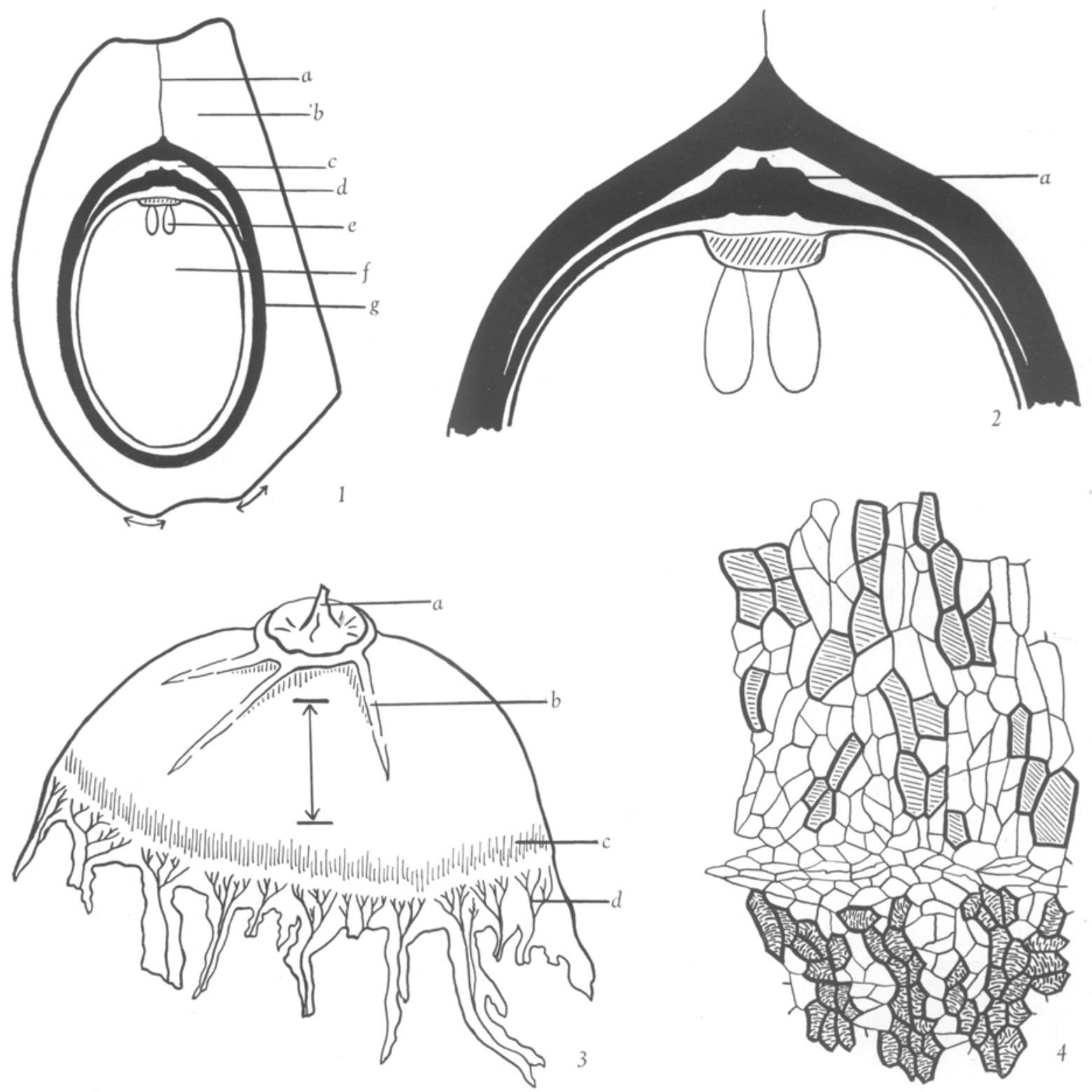

Fig. 1-4.-Fig. 1. Diagram of median longitudinal section of a mature ovule of Zamia indicating the relation of the nucellus to the other tissues. a, micropyle; b, fleshy layer of the integument; $c$, pollen chamber; $d$, nucellus; e, archegonium; f, female gametophyte; $g$, stony layer of the integument. Fused with the inner surface of the stony layer is the remnant of the inner fleshy layer. Arrows at the base of the ovule indicate the distribution of the integumentary stomata. $\times$ 3.5.-Fig. 2. Enlarged portion of fig. 1 to show the free portion of the nucellus and its lateral fusion to form the integument-nucellus complex. a, nucellus.-Fig. 3. Diagram of post-fertilization stage nucellus removed from the ovule. The area between the tannin zone (c) and the vein endings (d) marks the separation of the free part of the nucellus and the integument-nucellus complex. Arrow indicates the distribution of the stomata. This area covers from 3-4 mm. a, nucellar beak; b, path made by the germinating pollen tube through the nucellus.-Fig. 4. Cellular diagram from camera lucida drawing of the transition area between the free and attached parts of the nucellus. Note the proximity of the tannin cells (shaded) and the terminal tracheids of the vein endings. $\times 140$.

ovules, the cells of the central area and of the basal area (of the free part of the nucellus) are about the same size; but only the central area has sto. mata. At the basal region the guard cells disappear concomitantly with the appearance of a zone of tan- nin cells (fig. 3 c). The tannin cells exhibit a complete developmental series as the region in which they occur is examined from base to apex. In the portion of the tannin zone nearer the apex the transition from normal epidermal cell to tannin cell is 
marked only by a slight yellow coloration of the tannin initial. Basally the cells have a more intense coloration but retain conspicuous nuclei and cytoplasm. In the basal part of the zone the tannin cells are a deep reddish-brown in color and many lack organized cell contents. The tannin zone extends down to the junction of the nucellus with the integument (fig. 3, 4).

The fused integument-nucellus complex is supplied with a much branched vascular system which extends up to the point of separation of the integument and nucellus, and there ends abruptly. When the free portion of the nucellus is removed from the ovule, some of the integument-nucellus complex is torn free and remains attached to the nucellus (fig. 3 ). Microscopic examination reveals that the vein endings abut directly upon the basalmost cells of the free area. A ring of tracheids is thus formed which surrounds the ovule and the endings characteristically mark the junction point. In rare cases several of the terminal tracheids were found to extend into the free area of the nucellus, clearly indicating that a portion of the vascular tissue of the integument-nucellus complex is of nucellar origin. The question of whether the nucellus is vascularized has received the attention of several investigators, with conflicting reports recorded in the literature. Stopes (1905) studied a number of cycads with special emphasis on Cycas circinalis. She states, "The first thing to be established was the fact that the inner of the two series of vascular bundles penetrating the ovule and generally termed the "nucellar" series was truly integumentary. The nucellus itself was found to be entirely devoid of vascular tissue throughout." Although this quotation refers to Cycas, mention is made that these observations were confirmed with a number of other genera. Kershaw (1912) in describing Bowenia spectabilis mentions that in some ovules the veins were observed to enter the free part of the nucellus and he concludes that the nucellus is vascularized. The observation here presented for Zamia tends to support the statement of Kershaw.

The epidermal cells of the nucellus of a mature ovule are, in surface view, elongate and thickwalled and possess numerous wide, simple pits. The guard cells are smaller than the other epidermal cells and are often set diagonally to the parallel rows formed by the rest of the epidermis. The walls of the guard cells (fig. 7) exhibit the peculiar sculpturing, due to irregular thickening, which is often characteristic of the stomata of leaves of xerophytic plants. In some instances the stomata are surrounded by well formed subsidiary cells but more often these are lacking.

The individual guard cells average $20 \mu$ in width and $63 \mu$ in length. However, the range of sizes is surprisingly large; from 10-27 $\mu$ in width and from 38-84 $\mu$ in length. Upon reexamination, with a larger number of ovules, enough exceptions were found to the $4: 1$ ratio previously described between length and width (Shapiro, 1949) to render such a correlation invalid.

In cross section (fig. 9, 10) the stomata are slightly sunken and about the same thickness as the surrounding epidermal cells. One striking irregularity is the complete absence of a sub-stomatal chamber. In most cases the guard cells are perfectly continuous on their inner surface with the underlying parenchyma. Rarely, a small intercellular space is present between the guard cells (fig. 9). When such an intercellular space occurs, it is never more than half the thickness of the guard cells and is usually considerably less. The entire epidermal layer of the nucellus is covered by a very prominent cuticle (fig. 9, 10). In many instances the guard cells are physiologically isolated from the adjoining epidermal cells because of the heavy infiltration of cutin into the radial walls (fig. 9).

In all the material examined the stomatal aperture was very small and there is evidence that, as an open pore, it does not exist in many of the stomata. Serial sections through a pair of guard cells usually reveals that an unbroken cuticle completely covers the cells. This suggests that, although a small space may exist between the cell walls proper, a functional aperture is not present.

Despite the apparent immobility of the guard cells and the loss of function which this implies, the guard cells in fresh material contain large, spherical plastids which exhibit a positive test for starch when stained with iodine. A positive starch test is demonstrated only by the guard cells; the other epidermal cells never contain plastids or show starch accumulation. It appears that the stomata have retained the enzymes necessary for starch synthesis even though they have lost certain structural features. It has not as yet been possible to determine whether chlorophyll is present in the guard cells, but the possibility of these cells engaging in photosynthesis is extremely remote. The very thick integument and narrow micropyle in addition to the method of arrangement of the ovules in the strobilus, would very effectively prevent any light from reaching the nucellus. The starch accumulation which occurs in the guard cells must therefore be a result of conduction of sugars to these cells by diffusion through the parenchyma of the nucellus.

In the ontogeny of the ovule of Zamia floridana (Smith, 1910), formation of the nucellus precedes that of the integument. The former first appears as a single hypodermal cell which enlarges and exhibits more intense staining reactions than do the surrounding cells. Repeated division of this hypodermal cell gives rise to the body of the nucellus. The epidermis of the nucellus develops from divisions of the epidermis of the sporophyll. The integument is initiated at a stage when the nucellus 

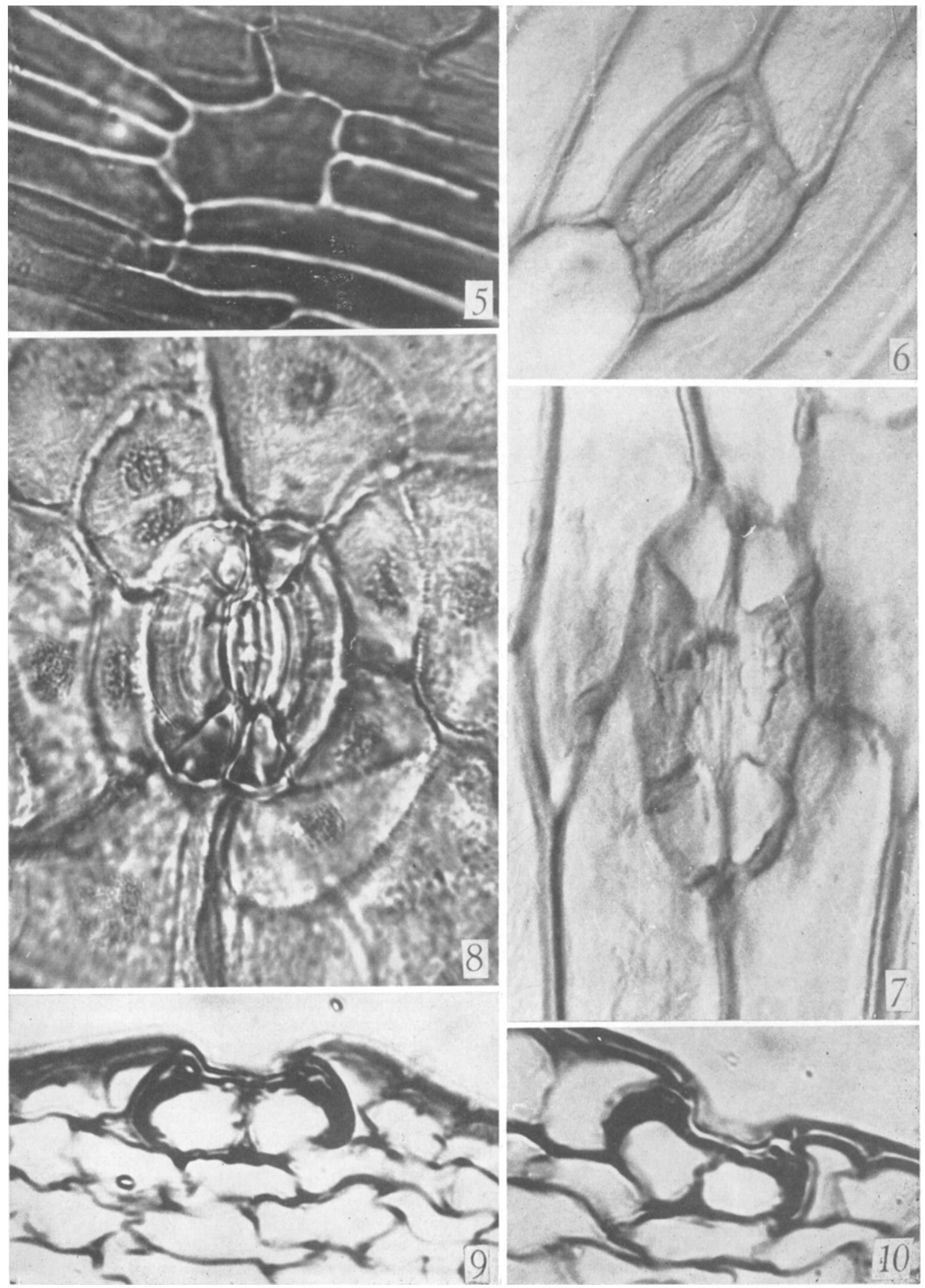
is evident as a small protuberance above the surface of the sporophyll. As with the nucellus, the body of the integument has its origin in hypodermal tissue with the epidermis again being formed from the epidermis of the sporophyll. The integument develops immediately lateral to the nucellus and as the epidermis of the two tissues is directly continuous and has a common origin, the integument was examined for the presence of stomata. No stomata could be found on the inner epidermis of the integument-that surface facing the nucellus and with which the nucellus is joined. On the outer epidermis of the integument no stomata were found at either the apical (micropylar) end or in the central region of the ovule. However, a scattered few were observed near the very base of the ovule at the point of attachmnt of the ovule with the sporophyll (fig. l, arrows). These stomata (fig. 8) are more deeply sunken than are those of - the nucellus. The integumentary stomata contain large plastids and appear capable of functioning in that they possess an open stomatal aperture. Whereas subsidiary cells are usually lacking with the nucellar stomata, they are invariably associated with the stomata found on the integument. In all of these features the integumentary stomata exhibit a marked resemblance to the stomata present on the leaflets of Zamia (Lamb, 1923).

Histogenesis of the stomata.-Development of the guard cells from the epidermis of the nucellus ap. pears to follow the same pattern as that established for many gymnosperm leaves. Cross (1942) and Tetley (1936) have been able to identify the guard cell mother cell because of its slightly sunken position and distinctive shape. Cells with these characteristics are distinguishable in the nucellus of Zamia. They are strikingly shorter than the surrounding cells and are obviously depressed below the surface (fig. 5). Each of the mother cells divides to form the two immature guard cells (fig. 6) which then differentiate into the typical stoma (fig. 7).

The exact stage in development of the nucellus at which the stomatal mother cells first appear has not been determined. Well developed guard cells have been found in ovules in which the gametophyte is but $2 \mathrm{~mm}$. in diameter. However, once the production of stomata is initiated the process is a progressive one. New guard cells continue to be formed for the entire life of the tissue. The nucellus of fertilization stage ovules has mature guard cells and guard cell mother cells within a few cells of one another. Mature ovules with large embryos still contain both mature and juvenile stomata even though the nucellus exhibits signs of dessication and certainly has ceased to grow. In all likelihood the immature stomata found on mature ovules never complete their development. Such a prolonged, progressive differentiation of stomata is very unlike that which occurs in the integument of the ovule or in the leaves of Zamia. Johnson (1943) describes progressive stomatal formation for leaves of Zamia floridana. The period of progressive formation is limited to very early stages of development and constitutes but a small fraction of the total time necessary for leaf maturation. The integumentary stomata again resemble the foliar stomata in that their production is completed within a relatively short time and at an early stage in development. The integument of prepollination stage ovules appears to have its full complement of stomata and all are completely mature.

Variability.-The initial observations which led to this study were made with detached ovules from a small collection made in 1946. All of the ovules then examined possessed nucellar and integumentary stomata. A considerable variation in total number of stomata on any one nucellus was noted. In some instances only two or three stomata were present; in others there were as many as fortv-five stomata present. Variations in total number of stomata also occur on the integuments but within a much more narrow range. Subsequent examination of larger collections which included complete strobili confirmed the differences in range for nucellus and integument and disclosed that stomata are often entirely absent from the nucellus. Preliminary investigation of this variability reveals that all the ovules of a single strobilus are probably uniform in possessing or lacking stomata on the nucellus. The absence of stomata on the nucellus apparently has no affect upon their presence on the integument; every ovule thus far examined has contained integumentary stomata. If the stomata on the nucellus and integument are regarded as vestigial characters, it appears as though they are each controlled by an independent genetic mechanism. The distinct dissimilarities previously mentioned such as degree of depression and presence of subsidiary cells in the integument and their absence in the nucellus, are added justification for the hvpothesis of separate genetic control of nucellar and

Fig. 5-10.-Fig. 5. Stomatal mother cell from nucellus of post-pollination stage ovule. $\times 850 .-$ Fig. 6. Pair of young guard cells from nucellus of post-fertilization stage ovule. Note the beginning of thickening of the walls. $\times 950 .-F i g$. 7. Mature stoma from the nucellus of a post-fertilization stage ovule. Note the sculpturing of the walls and the apparent lack of depression of the stoma. The stomatal aperture is insignificant. $\times 1000 .-F i g$. 8. Mature stoma from the integument of a mature ovule. Note the subsidiary cells and the canopy which they form above the much sunken stoma. $\times 800$. Fig. 9. Transverse section of a stoma from the nucellus of a mature ovule. The substomatal chamber has been reduced to the size of an intercellular space. Note the prominent cuticle and slight depression of the guard cells. $\times 825$. Fig. 10. Transverse section of a pair of guard cells from the nucellus. Note the infiltration of cutin into the radial walls of the guard cells. The cuticle covers the entire surface of the cells. $\times 825$. 
integumentary stomata. The presence of stomata on the integument and absence on the nucellus of certain fossil cycads also lends credence to this idea.

The absence of stornata on the nucellus is not associated with any other recognizable nucellar or ovular changes. The rate of development, cell size and shape and extent of tannin formation are the same in both stomatal and astomatal nucelli. An explanation suggests itself for the presence of stomata on the nucellus of some plants and not on others. There may exist two races of Zamia floridana differing only in that one has retained the stomata as a vestige while the other has lost it in the course of evolution. A more extensive study of this variability is planned for the future.

Discussion.-When considered from a phylogenetic standpoint, the occurrence of stomata on the megasporangium of a gymnosperm discloses certain interesting relationships with the lower groups. The nucellus is regarded as homologous with the megasporangium of the heterosporous pteridophytes and, to a more remote extent, to the homosporous sporangia of both bryophytes and pteridophytes. The Bryophyta are generally now believed to be a divergent group, significantly isolated from the evolutionary lines of the vascular plants. Bryophytes do, however, possess stomata as a sporangial character. As an example of the higher liverworts, Anthoceros is known to have stomata on the wall of the sporangium. Stomata are also common on the walls of the sporangia (capsules) of many of the true mosses, and in some instances are a diagnostic feature in classification. In accord with the concept of the Bryophyta as an evolutionarily unfruitful group, the stomata found on the sporangia of these plants can in no way be phylogenetically ralated to the stomata found on the sporangia of spermatophytes. As a sporangial character, stomata must therefore have had at least two distinctly independent origins in evolution; one probably in an ancestor of modern bryophytes, another in a primitive vascular plant. To secure more information about the latter point of origin the literature dealing with fossil vascular plants has been surveyed. Rhynia (Kidston and Lang, 1917), one of the most ancient vascular plants, has a simple stem the terminal portion of which is expanded and elongated to form the sporangium. Stomata are present on the stem up to the transition area, but have not been observed on the epidermis of the sporangium proper. Sporangia of a number of fossil ferns have been sufficiently well preserved to show cellular detail, but none of these are recorded as containing stomata. A survey of modern pteridophytes reveals the same absence that was demonstrated by the fossil forms; not a single modern species is reported in the literature as bearing stomata on the sporangium. Homosporous and heterosporous members have been investigated and the entire division appears to lack the character uniformly.

Arnold (1948) described the cutinized membranes of some pteridosperm seeds. The prepared slides of these seeds were very kindly loaned to the author by Prof. Arnold and were critically examined for stomata. Many of the specimens had parts of the nucellus and integument in excellent state of preservation. Although the shape and arrangement of the epidermal cells of the fossil nucellus very much resembled those found in Zamia, no stomata were found. However, as the entire surface of the fossil material could not be studied, the presence of stomata on the seeds cannot be completely ruled out. The extreme variability in num. ber of stomata previously mentioned for Zamia may also have been a factor in not detecting stomata on the fossil seeds. Thomas (1933) presents an extensive treatment of pteridosperms in which stomata are repeatedly described on both the inner and outer epidermis of the cupules which surround the seeds. The testa of the seed is reported as being smooth and no mention is made of stomata.

Wieland (1906) reported on a number of fossil cycads and although cellular details of the ovules are presented, stomata are not described on either the nucellus or integument. Beania, an extinct cy. cad which bears a close resemblance to Zamia in certain characteristics, does contain stomata on the integument of the ovule (Harris, 1941). Cutinized remains of the nucellus of Beania show good cellular detail but no stomata have been described on this surface.

Because of the incomplete nature of fossil material, negative evidence regarding a structure cannot be considered conclusive. Conclusions are necessarily presented on a tentative basis and subject to change as new information becomes available. The absence of stomata from fossil and living members of the Pteridophyta would appear to indicate that sporangial stomata did not orig. inate within this group. Although integumentary stomata are present in some fossil cycads, the occurrence of nucellar stomata cannot be demonstrated for any fossil described. More intensive study may reveal the character to occur on fossil seeds or possibly may indicate that nucellar stomata are the result of a comparatively recent mutation.

The question of whether Zamia is unique among the cycads in the possession of nucellar stomata cannot be answered at this time. Chamberlain (1919) considered Zamia to be the most modern of the cycads, and Cycas the most primitive. Several ovules of Cycas revoluta were examined but none contained stomata. In view of the variability which might be expected, a larger number of specimens is necessary for conclusive results. A review of the literature indicates that although the cellular structure of the nucellus and integument has been 
described for a number of cycad genera (Chamberlain, 1906, 1912, 1935; Kershaw, 1912; Lang, 1900; Treub, 1885), stomata have not been reported. Chamberlain (1906) states that stomata are not present on the integument of Dioon. However, the much restricted distribution of stomata on the integument of Zamia makes it possible that the stomata have been overlooked in Dioon and other genera.

\section{SUMMARY}

Stomata are described on the nucellus and integ. ument of the ovule of Zamia. The nucellar stomata occur over the major part of the free portion of the nucellus; the integumentary stomata are restricted to the very base of the ovule. The number of stomata is more variable on the nucellus than on the integument and some strobili appear to lack nucellar stomata entirely. The integumentary stomata resemble the foliar stomata in many respects and differ considerably from the nucellar stomata. Nucellar and integumentary stomata contain plastids and can synthesize starch. The hypothesis is presented that the nucellar and integumentary stomata are controlled by separate genetic mechanisms. Fossil members of the psilophytales, ancient ferns, and pteridosperms are not reported to have stomata on the sporangia. Modern ferns also lack stomata as a sporangial character. Beania, a fossil cycad contains integumentary stomata, but no fossil has been described with nucellar stomata.

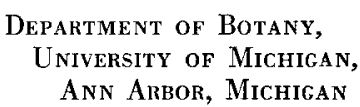

\section{LITERATURE CITED}

Arnold, C. A. 1948. Some cutinized seed membranes from the coal-bearing rocks of Michigan. Bull. Torrey Bot. Club 75: 131-146.

Chamberlain, C. J. 1906. The ovule and female gametophyte of Dioon. Bot. Gaz. 42: 321-358.

1912. Morphology of Ceratozamia. Bot. Gaz. 53: 1-19.

. 1919. The living cycads. Univ. of Chicago Press. Chicago.

- 1935. Gymnosperms structure and evolution. Univ. of Chicago Press. Chicago.

Cross, G. L. 1942. Structure of the apical meristem and development of the foliage leaves of Cunninghamia lanceolata. Amer. Jour. Bot. 29: 288-301.

Harris, T. M. 1941. Cones of extinct Cycadales from the Jurassic rocks of Yorkshire. Phil. Trans. Roy. Soc. London B. 231: 75-98.

Johnson, M. A. 1943. Foliar development in Zamia. Amer. Jour. Bot. 30: 366-378.

Kershaw, E. M. 1912. Structure and development of the ovule of Bowenia spectabilis. Ann. Bot. 26: 625-646.

Kidston, R., and W. H. Lang. 1917. Old Red Sandstone plants showing structure; from the Rhynie chert bed. Trans. Roy. Soc. Edinburgh 51: 761-784.

Lamb, Sister M. Alice. 1923. Leaflets of Cycadaceae. Bot. Gaz. 76: 185-202.
LANG, W. H. 1900. Studies in the development and morphology of cycadean sporangia. II. The ovule of Stangeria paradoxa. Ann. Bot. 14: 281-306.

Oliver, F. W., aNd D. H. Scott. 1903. On Lagenostoma Lomaxi, the seed of Lyginodendron. Proc. Roy. Soc. London 71: 477-481. Reprinted in Ann Bot. 17: 625629. 1903.

Smith, Frances G. 1910. Development of the ovulate strobilus and young ovule of Zamia floridana. Bot. Gaz. 50: 128-141.

Shapiro, S. 1949. The presence of stomata on the nucellus of Zamia floridana. (Abstract) Amer. Jour. Bot. 36: 803.

Stopes, Marie C. 1905. On the double nature of the cycadean integument. Ann. Bot. 19: 561-566.

Tetley, Ursula. 1936. Tissue differentiation in some foliage leaves. Ann. Bot. 50:523-557.

Thomas, H. H. 1933. On some pteridosperms from the Mesozoic rocks of South Africa. Phil. Trans. Roy. Soc. London B. 222: 193-265.

Treub, M. 1885. Recherches sur les Cycadées. II. Développement de l' ovule et du sac embryonnaire dans le Ceratozamia longifolia Mig. Ann. du Jardin Bot. Buitenzorg 2:32-53.

Wifland, G. R. 1906. American fossil cycads. Carnegie Inst. Washington Publ. No. 34. 